\title{
Optimal Scheduling Strategy for Energy Consumption Minimization of Hydro-Thermal Power Systems
}

\author{
Jiekang WU \\ School of Electrical Engineering, Guangxi University, Nanning, China \\ Email:wujiekang@163.com
}

\begin{abstract}
A comparison analysis based method for computing the water consumption volume needed for electric energy production of optimal scheduling in hydro-thermal power systems is presented in this paper. The electric energy produced by hydroelectric plants and coal-fired plants is divided into 4 components: potential energy, kinetic energy, water-deep pressure energy and reservoir energy. A new and important concept, reservoir energy, is proposed, based on which is divided into a number of water bodies, for example 3 water bodies, and a reservoir is analyzed in a new way. This paper presents an optimal scheduling solution of electric energy production of hydro-thermal power systems based on multi-factors analytic method, in which some important factors, such as load demand, reservoir in-flow, water consumption volume increment rate of hydroelectric plants or converted from coal-fired plants, and so on are given to model the objective function and the constraints. A study example with three simulation cases is carried out to illustrate flexibility, adaptability, applicability of the proposed method.
\end{abstract}

Keywords: hydro-thermal power systems, optimal electric energy production, water consumption volume

\section{Introduction}

Water is one of the important renewable energy sources and coal is a non-renewable energy source. For optimal scheduling of hydro-thermal power systems, it is the first thing that water must have much more priority to be used for electric energy production than coal so as to supply the demand load. It is an important study task how to minimize the sum of water consumption volume of the hydroelectric plant and water consumption volume converted from the coal-consumed volume of coal-fired plants in hydro-thermal power system dispatch.

In modeling electric energy production of hydroelectric plants, some pioneer did many significant works. For the portfolio management of a scandinavian power supplier, a linear stochastic model with hydraulic power plants under uncertain inflow and market price conditions is introduced [1]. In [2], price uncertainty by scenarios and a model for maximizing risk-adjusted profit within an asset-liability framework is represented. A new multi-loop-cascaded governor, with which the perform- ance specifications and stability margins are improved significantly even in the presence of some uncertainties, is proposed to use for hydro turbine control [3] and some other stochastic programming models are proposed to represent the energy systems [4]. However, with the achievements in recent liberalization of the electricity market, the discussion about improving the assumptions and considering further aspects of actual system operations is far from ending.

Some works have done for the optimal scheduling solution of hydro-thermal power systems. There are many computational methods for the solution of some difficult optimization problem such as dynamic programming [5][6], network flow [7-9], standard mixed integer programming methods [10-12], and modern heuristic algorithms [13][14]. Although dynamic programming is flexible and can handle the constraints better in a straightforward way, the "curse of dimensionality" still remains, and the main drawback of using dynamic programming for a realistic systems with multiple reservoirs 
and cascaded hydro plants still exists [14]. Network flow would be the natural way to model hydro systems. Its main drawback, however, is its inability to deal with discontinuous operating regions and discrete operating states [15]. Mixed integer programming is only suitable for small systems due to size limitations. Modern heuristic algorithms do not require such conditions that the objective function has to be differentiable and continuous, so these methods are considered as effective tools for non- linear optimization problems such as short-term scheduling of hydro systems. Particle swarm optimization (PSO) is one of the modern heuristic algorithms. PSO has attracted great attention due to its features of easy implementation, robustness to control parameters and computation efficiency compared with other existing heuristic algorithms, and has been successfully applied to hydroelectric optimization scheduling problems [16-20]. Some stochastic approaches are also used for the solution of the cascaded hydro plants problem [21-22].

This paper presents a novel analysis method for modeling hydro-energy conversion and computing water consumption volume of optimal electric energy production in large-scale hydro-thermal power systems, taking some energy components, such as potential energy, kinetic energy, water-deep pressure energy and reservoir energy into consideration, and also taking some influence factors, such as load demand, reservoir in-flow, water consumption volume increment rate, and so on, into account.

\section{Hydro-Energy Conversion}

In a large-scale reservoir, if there is a hydro-mechanical-electric coupling system, with a shaft leading the reservoir water through penstock to a hydro turbine, the potential, kinetic and water-deep energy in water is harnessed by the HME coupling system and create electricity from it. For each HME system, the amount of electric energy transformed form hydro energy in reservoir depends on the forces applied on the water body in intake and tailrace of the pressure tunnel. In intake of the pressure tunnel, basing on the traditional analysis method, there is gravitational force corresponding to the potential energy, kinetic force corresponding to kinetic energy and pressure force corresponding to water-deep pressure energy.

In this paper, besides three traditional forces there are another three reservoir forces applied to the water body in intake if a reservoir is divided into three water bodies when modeling the hydroelectric energy of large-scale reservoir. These three reservoir forces applies to the water bode in intake of a pressure tunnel and do work in respective part, which is called 'reservoir energy' in this paper, as shown in Figure 1.

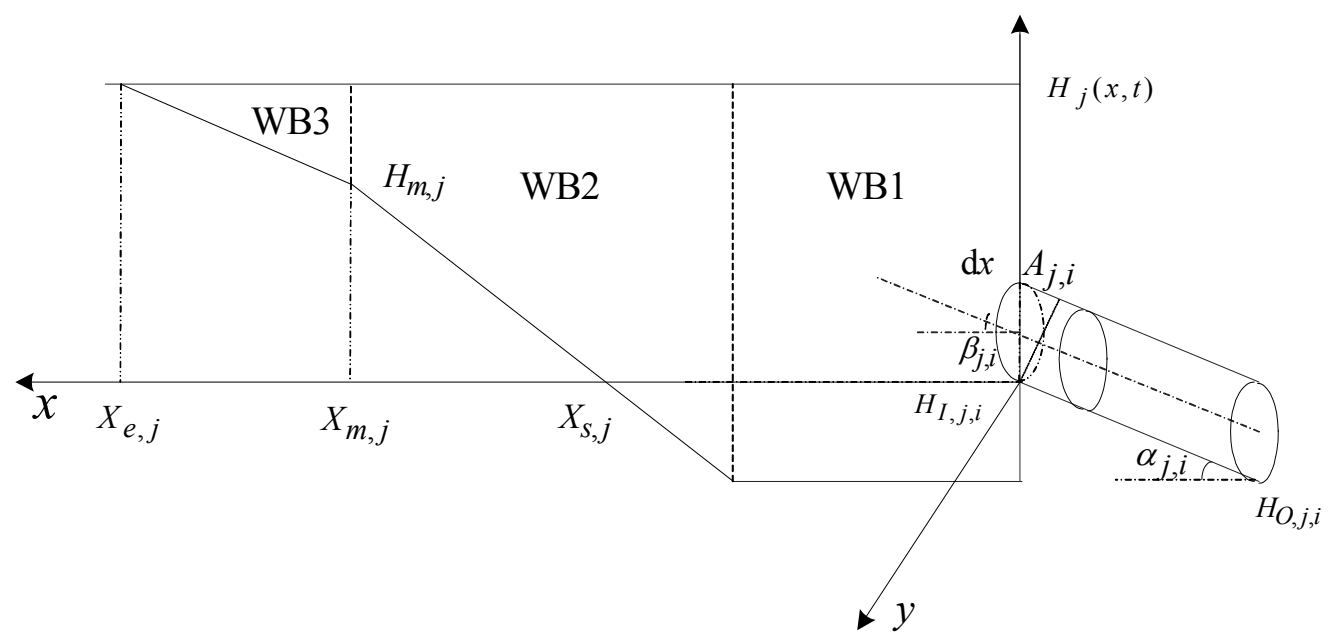

Figure 1. Divided water bodies of a large-scale reservoir 
Because of difference in kinetic energy, potential energy, energy converted from water-deep pressure energy, the energy converted from self-weight, reservoir energy, there is a part of energy transformed into electric energy. For a unit $i$ in plant $j$, the electric energy converted by a HME system in unit time(for example one second) may be expressed in a form of kilo-watt may be formulated in MWs:

$$
E_{H, j, i}\left(H_{j}, Q_{G, j, i}\right)=f_{1}+f_{2}+f_{3}+f_{4}+f_{5}+f_{6}
$$

where

$$
\begin{aligned}
& f_{1}\left.=9.81\left[\left(H_{j}(x, t)-H_{I, j, i}\right)-p_{O, j, i}\right)\right] Q_{G, j, i} \\
& f_{2}=9.81 * \frac{1}{2 g}\left[v_{I, j, i}^{2}-v_{O, j, i}^{2}\right] Q_{G, j, i} \\
& f_{3}=9.81\left[H_{I, j, i}-H_{O, j, i}(t)\right] Q_{G, j, i} \\
& f_{4}=\frac{9.81 X_{s, j} Y_{j}\left[H_{j}(x, t)-H_{I, j, i}\right]}{Y_{j}\left[H_{j}(x, t)-H_{I, j, i}\right]} . \\
& \sin \beta_{s, j} \cos \left(\alpha_{I, j, i}-\beta_{s, j}\right) \cos ^{2} \gamma_{s, j, i} \cdot Q_{G, j, i} \\
& f_{5}=\frac{9.81 Y_{j}\left(X_{m, j}-X_{s, j}\right)\left(2 H_{j}(x, t)-H_{m, j}-H_{I, j, i}\right)}{2 Y_{j}\left[H_{j}(x, t)-H_{I, j, i}\right]} . \\
& \quad \sin \beta_{m, j} \cos \left(\alpha_{I, j, i}-\beta_{m, j}\right) \cos ^{2} \gamma_{m, j, i} \cdot Q_{G, j, i} \\
& f_{6}=\frac{9.81 Y_{j}\left(X_{e, j}-X_{m, j}\right)\left(H_{j}(x, t)-H_{m, j}\right)}{3 Y_{j}\left[H_{j}(x, t)-H_{I, j, i}\right]} . \\
& \quad \sin \beta_{e, j} \cos \left(\alpha_{I, j, i}-\beta_{e, j}\right) \cos ^{2} \gamma_{e, j, i} \cdot Q_{G, j, i}
\end{aligned}
$$

where $f_{1}$ is energy converted from water-deep pressure energy, $f_{2}$ is energy converted from kinetic energy, $f_{3}$ is energy converted from potential energy, $f_{4}-f_{6}$ is energy converted from reservoir energy. $Q_{G, j, i}$ is generation flow of generator $i$ in plant $j, \alpha_{j, i}$ is the angle of the pressure tunnel for each generating unit, $H_{j}(x, t)$ is water-storage level elevation in reservoir $j$ at time $t, H_{I, j, i}$ is a position elevation of the intake of the pressure tunnel relative to sea level, $\beta_{s, j}, \beta_{m, j}$ and $\beta_{e, j}$ is angle between $x$ direction and the line passing through the gravity center of water body WB1, WB2, WB3 and axial origin respectively, $D_{j, i}$ and $A_{j, i}$ is diameter and sectional area of the pressure tunnel in the intake respectively, $j$ denotes plant index, $X_{s, j}, X_{m, j}$ and $X_{e, j}$ is starting point of water body WB1, WB2 and WB3 in $x$ direction, $Y_{j}$ is width of the dam, $\gamma_{s, j, i}, \gamma_{m, j, i}$ and $\gamma_{e, j, i}$ is angle of the water body WB1, WB2 and WB3 between the center line of $x$ direction and the pressure tunnel of unit $i$ in reservoir $j$ respectively, $T_{\max , j, i}$ is maximal utilization hours for the rated capacity of hydroelectric generating unit $i$ in hydroelectric plant $j, N_{R, j}$ is year number of a scheduling period.

The electric power $P_{H, j, i}$ of a generator is formulated:

$$
P_{H, j, i}=\frac{E_{H, j, i}}{T}
$$

where $T$ is scheduling period of the hydroelectric plants.

For a unit time( one second), $P_{H, j, i}=E_{H, j, i}$.

\section{Energy Consumption of Electric Power Production}

\subsection{Water Consumption Volume Increment Rate}

For a hydropower-driven generator, the variation of electric energy is obtained by differentiating Equation (1) with respect to $Q_{G, j, i}$ :

$$
\begin{aligned}
\Delta E_{H, j, i} & =\left[\partial f_{1}+\partial f_{2}+\partial f_{3}+\partial f_{4}+\partial f_{5}+\partial f_{6}\right] \cdot \Delta Q_{G, j, i} \\
= & \frac{\partial f_{1}+\partial f_{2}+\partial f_{3}+\partial f_{4}+\partial f_{5}+\partial f_{6}}{T} \cdot \Delta W_{H, j, i}
\end{aligned}
$$

where

$$
\begin{aligned}
& \left.\Delta f_{1}=9.81\left[\left(H_{j}(x, t)-H_{I, j, i}\right)-p_{O, j, i}\right)\right] \\
& \Delta f_{2}=9.81 * \frac{1}{2 g}\left[v_{I, j, i}^{2}-v_{O, j, i}^{2}\right] \\
& \Delta f_{3}=9.81\left[H_{I, j, i}-H_{O, j, i}(t)\right]
\end{aligned}
$$




$$
\begin{gathered}
\Delta f_{4}=\frac{9.81 X_{s, j} Y_{j}\left[H_{j}(x, t)-H_{I, j, i}\right]}{Y_{j}\left[H_{j}(x, t)-H_{I, j, i}\right]} . \\
\Delta f_{5}=\frac{9.81 Y_{j}\left(X_{m, j}-X_{s, j}\right)\left(2 H_{j}(x, t)-H_{m, j}-H_{I, j, i}\right)}{2 Y_{j}\left[H_{j}(x, t)-H_{I, j, i}\right]} . \\
\Delta f_{6}=\frac{9.81 Y_{j}\left(X_{e, j}-X_{m, j}\right)\left(H_{j}(x, t)-H_{m, j}\right)}{3 Y_{j}\left[H_{j}(x, t)-H_{I, j, i}\right]} \\
\sin \beta_{m, j} \cos \left(\alpha_{I, j, i}-\beta_{m, j}\right) \cos ^{2} \gamma_{m, j, i} \\
\sin \beta_{e, j} \cos \left(\alpha_{I, j, i}-\beta_{e, j}\right) \cos ^{2} \gamma_{e, j, i}
\end{gathered}
$$

Water consumption volume increment rate is defined to be a ratio of the variation of the water consumption volume and the variation of electric power output of a hydropower-driven generator:

$$
\begin{aligned}
\lambda_{H, j, i} & =\frac{\Delta W_{H, j, i}}{\Delta E_{H, j, i}}=\frac{T}{\partial f_{1}+\partial f_{2}+\partial f_{3}+\partial f_{4}+\partial f_{5}+\partial f_{6}} \\
& =\frac{T \Delta Q_{G, j, i}}{\left(\partial f_{1}+\partial f_{2}+\partial f_{3}+\partial f_{4}+\partial f_{5}+\partial f_{6}\right) \Delta Q_{G, j, i}} \\
& =\frac{T \Delta Q_{G, j, i}}{\Delta E_{H, j, i}}
\end{aligned}
$$

\subsection{Coal Consumption Volume Increment Rate}

For a thermal power-driven generator, the coal consumption volume is formulated as a quadratic function of electric power, as shown in the following form:

$$
F_{T, k, l}=a_{T, k, l} E_{T, k, l}^{2}+b_{T, k, l} E_{T, k, l}+c_{T, k, l}
$$

where $F_{T, k, l}$ and $E_{T, k, l}$ is respectively coal consumption volume and electric power of a thermal power-driven generator; $a_{T, k, l}, b_{T, k, l}, c_{T, k, l}$ is respectively coefficient of coal consumption volume of a thermal power-driven generator.

The variation of coal consumption volume is obtained by differentiating Equation (25) with respect to $E_{T, j, i}$ :

$$
\Delta F_{T, k, l}=\left(2 a_{T, k, l} E_{T, k, l}+b_{T, k, l}\right) \Delta E_{T, k, l}
$$

Coal consumption volume increment rate is defined to be a ratio of the variation of the coal consumption volume and the variation of electric power output of a thermal power-driven generator:

$$
\lambda_{T, k, l}=\frac{\Delta F_{T, k, l}}{\Delta E_{T, k, l}}=2 a_{T, k, l} E_{T, k, l}+b_{T, k, l}
$$

\section{Optimal Scheduling Models for Hydro- Thermal Systems}

Water is one of renewable energy, which is an energy source that can be replenished in a short period of time, and is mainly used for electric energy production. Coal is non-renewable energy, which is an energy source that may be used up and cannot be recreated in a short period of time. In order to make as possible as best use of renewable resource, water must be placed on more prior consideration for electric energy production than coal. For this purpose, the objective of scheduling optimization of hydro-thermal power systems must minimize the water consumption volume consumed in electric energy production, including the water consumption volume consumed in hydro-electric plants and the water consumption volume exchanged from coal consumption volume consumed in coal-fired electric plants:

$$
\min \sum_{t=1}^{T}\left[\sum_{j=1}^{N_{H}} \sum_{i=1}^{N_{H G}} W_{H, j, i}+\sum_{k=1}^{N_{T}} \sum_{l=1}^{N_{T G}} \gamma_{T, k, l} F_{T, k, l}\right]
$$

where $N_{H}$ and $N_{H G}$ is respectively number of hydroelectric plants and hydro-driven generators in plant $j, N_{T}$ and $N_{T G}$ is respectively number of coal-fired electric plants and coal-fired generators, $\gamma_{T, k, l}$ is a coefficient exchanging coal consumption volume consumed in coal-fired electric plants into water consumption volume, and it is formulated:

$$
\gamma_{T, k, l}=\frac{\lambda_{H, a d v}}{\Delta F_{T, k, l} / \Delta E_{T, k, l}}
$$

where $\lambda_{H, a d v}$ is average water consumption volume increment rate of all hydro-driven generators: 


$$
\lambda_{H, a d v}=\frac{\sum_{j=1}^{N_{H}} \sum_{i=1}^{N_{H G}} \lambda_{H, j, i}}{N_{H} N_{H G}}
$$

The constraint conditions include:

1) Equality constraint for electric power of hydro-thermal power systems: at any time $t$, the sum of the electric power produced by hydro-driven generators and coal-fired generators must be hold to be equal to load-demanded power:

$$
\sum_{j=1}^{N_{H}} \sum_{i=1}^{N_{H G}} P_{H, j, i}(t)+\sum_{k=1}^{N_{T}} \sum_{l=1}^{N_{T G}} P_{T, k, l}(t)-P_{L}(t)=0
$$

where $P_{L}(t)$ is load-demanded power at any time $t$.

2) Equality constraint for electric energy of hydro-thermal power systems: in the scheduling period $T$, the sum of the electric energy produced by hydro-driven generators and coal-fired generators must be hold to be equal to load-demanded energy:

$$
\sum_{j=1}^{N_{H}} \sum_{i=1}^{N_{H G}} E_{H, j, i}(T)+\sum_{k=1}^{N_{T}} \sum_{l=1}^{N_{T G}} E_{T, k, l}(T)-E_{L}(T)=0
$$

where $E_{L}(T)$ is load-demanded energy in the scheduling period $T$.

3) Inequality constraint for active and reactive power of hydro-driven generators:

$$
\begin{aligned}
\underline{P}_{H, j, i} & \leq P_{H, j, i} \leq \bar{P}_{H, j, i} \\
\underline{Q}_{H, j, i} & \leq Q_{H, j, i} \leq \bar{Q}_{H, j, i}
\end{aligned}
$$

where $\underline{P}_{H, j, i}, \underline{Q}_{H, j, i}$ and $\bar{P}_{H, j, i}, \bar{Q}_{H, j, i}$ is respectively the lower and upper limited value of active and reactive power of hydro-driven generator $i$ in plant $j$.

5) Inequality constraint for active and reactive power of coal-fired generators:

$$
\begin{aligned}
& \underline{P}_{T, k, l} \leq P_{T, k, l} \leq \bar{P}_{T, k, l} \\
& \underline{Q}_{T, k, l} \leq Q_{T, k, l} \leq \bar{Q}_{T, k, l}
\end{aligned}
$$

where $\underline{P}_{T, k, l}, \underline{Q}_{T, k, l}$ and $\bar{P}_{T, k, l}, \bar{Q}_{T, k, l}$ is respec- tively the lower and upper limited value of active and reactive power of coal-fired generator $l$ in plant $k$.

6) Inequality constraint for generation flow:

$$
\underline{Q}_{G, j, i} \leq Q_{G, j, i} \leq \bar{Q}_{G, j, i}
$$

where $\underline{Q}_{G, j, i}$ and $\bar{Q}_{G, j, i}$ is respectively the lower and upper limited value of generation flow of hydro-driven generator $i$ in plant $j$.

7) Inequality constraint for coal consumption volume:

$$
F_{\text {down }, k} \leq \sum_{l=1}^{N_{T G}} F_{T, k, l} \leq F_{u p, k}
$$

where $F_{u p, k}$ and $F_{\text {down }, k}$ is maximal limit and minimal limit of coal consumption volume of coal-fired electric plant $k$ in the scheduling period $T$.

8) Inequality constraint for water consumption volume:

$$
W_{d o w n, j} \leq \sum_{i=1}^{N_{H G}} W_{H, j, i} \leq W_{u p, j}
$$

where $W_{u p, j}$ and $W_{\text {down,j }}$ is maximal limit and minimal limit of water consumption volume of hydro-electric plant $j$ in the scheduling period $T$.

9) Inequality constraint for water consumption volume and coal consumption volume: for a whole, the coal consumption volume exchanged using water consumption volume of all hydro-driven generators is required to be greater than that consumed by all coal-fired generators:

$$
\sum_{t=1}^{T} \sum_{j=1}^{N_{H}} \sum_{i=1}^{N_{H G}} \gamma_{C, j, i} W_{H, j, i}>\sum_{t=1}^{T} \sum_{k=1}^{N_{T}} \sum_{l=1}^{N_{T G}} F_{T, k, l}
$$

where $\gamma_{C, j, i}$ is a coefficient exchanging water consumption volume consumed in hydro-electric plants into coal consumption volume, and it is formulated:

$$
\gamma_{C, j, i}=\frac{\lambda_{T, a d v}}{\Delta W_{H, j, i} / \Delta E_{H, j, i}}
$$

where $\lambda_{T, a d v}$ is average coal consumption volume increment rate of all coal-fired generators: 


$$
\lambda_{T, a d v}=\frac{\sum_{k=1}^{N_{T}} \sum_{l=1}^{N_{T G}} \lambda_{T, k, l}}{N_{T} N_{T G}}
$$

At the same time, the water consumption volume exchanged from coal consumption volume of all coal-fired generators is required to be smaller than that consumed by all hydro-driven generators:

$$
\sum_{t=1}^{T} \sum_{j=1}^{N_{H}} \sum_{i=1}^{N_{H G}} W_{H, j, i}>\sum_{t=1}^{T} \sum_{k=1}^{N_{T}} \sum_{l=1}^{N_{T G}} \gamma_{W, k, l} F_{T, k, l}
$$

10) Equality constraint related to saved-water level: during high-water period, normal-water period, low water period, and flood period, saved-water level is required to be retained at a fixed value:

$$
H_{j}(t)= \begin{cases}H_{L P, j} & \text { for LP } \\ H_{H P, j} & \text { for HP } \\ H_{N P, j} & \text { for NP } \\ H_{F P, j} & \text { for FP }\end{cases}
$$

where $H_{L P, j}, H_{H P, j}, H_{N P, j}$ and $H_{F P, j}$ is a required saved-water level at time $t$ in reservoir $j$ for high-water period, normal-water period, low water period, and flood period respectively.

11) Equality constraint for variation of saved-water level: in the scheduling period $T$, the variation of saved-water level in reservoir $j$ is required to be equal to zero:

$$
\sum_{t=1}^{T} \sum_{j=1}^{N_{H}} \Delta H_{j}(t)=0
$$

12) Inequality constraint for water energy total: at time $t$, the water energy total of cascaded hydroelectric plants is required to be no smaller than a designed value:

$$
N_{R, j}\left(3600 * T_{\max , j, i}\right) \sum_{j=1}^{N_{H}} \sum_{i=1}^{N_{H G}} E_{H, j, i}\left(H_{j}, Q_{G, j, i}\right) \geq E_{A}
$$

where $E_{A}$ is designed value of the water energy total of cascaded hydroelectric plants:

$$
E_{A}=N_{R, j}\left(3600 * T_{\max , j, i}\right) \sum_{j=1}^{N_{H}} \sum_{i=1}^{N_{H G}} E_{H, j, i}\left(H_{D, j}, Q_{G N, j, i}\right)
$$

where $H_{D, j}$ and $Q_{G N, j, i}$ is respectively the designed saved-water level and normal generation flow of hydro-driven generator $i$ in plant $j$.

13) Inequality constraint for minimal saved-water level:

$$
H_{j}(x, t)-H_{I, j, i} \geq p_{O, j, i}
$$

\section{Study Examples and Analysis}

In this paper, Guangxi electric power system including Hongshuihe hydroelectric stations in Hongshuihe river is taken for a studying example. The data for Hongshuihe hydroelectric plants and coal-fired electric plants in Guangxi electric power system is shown in Table 1 and Table 2 respectively. In the following section, three cases are given to illustrate the component and factor analytic method for optimal electric energy production of thermal power systems in one hour.

According to the objective to minimize the sum of the water-consumed volume used for electric energy production in 8 cascaded hydroelectric plants and the water-consumed volume converted from coal-consumed volume by 12 coal-fired plants, the plant with smaller water-consumed volume or coal-water-consumed volume is the first one to be scheduled to generate. As shown in Table 1 and 2, the plants with greater rated install capacity have smaller water-consumed volume or coal to water volume in per unit electric energy output, while the plants with smaller rated install capacity have greater water-consumed volume or coal to water volume in per unit electric energy output.

In high in-flow period, the reservoir inflow in each cascaded hydroelectric plant is assumed to be high. In this case, the water flow and water volume for electric energy production in each cascaded reservoir is available. Because of much more available water flow for electric energy production and smaller water-consumed volume 
Table 1. The data for Hongshuihe hydroelectric plants

\begin{tabular}{|c|c|c|c|c|c|c|c|c|c|}
\hline Item & Unit & $\begin{array}{l}\text { Tian sheng } \\
\text { qiao No.1 }\end{array}$ & $\begin{array}{l}\text { Tian sheng } \\
\text { qiao No.2 }\end{array}$ & Ping ban & Long tan & Yan $\tan$ & Da hua & Bai long tan & Le tan \\
\hline Plant No. & & H1 & $\mathrm{H} 2$ & $\mathrm{H} 3$ & $\mathrm{H} 4$ & H5 & H6 & $\mathrm{H} 7$ & $\mathrm{H} 8$ \\
\hline Reservoir Regulation & & over-years & daily & daily & over-years & seasonal & runoff & runoff & runoff \\
\hline Regulation capacity & $\mathrm{Gm}^{3}$ & 5.796 & 0.0184 & 0.0268 & 11.15 & 2.34 & 0.043 & 0.047 & 0.46 \\
\hline Electric energy produced in one year & $\mathrm{G} \cdot \mathrm{kWh}$ & 5.62 & 8.20 & 1.60 & 15.6 & 5.66 & 2.06 & 0.95 & 2.99 \\
\hline Rated Installe capacity & MW & $4 * 300$ & $6 * 200$ & $3 * 135$ & $7 * 600$ & $4 * 302.5$ & $4 * 114$ & $6 \times 32$ & $4 * 150$ \\
\hline Generation flow & $\mathrm{m}^{3} / \mathrm{s}$ & 301.3 & 139.8 & 440.29 & 556 & 580 & 606 & 377.5 & 863.9 \\
\hline Water head & $\mathrm{m}$ & 110.7 & 176.0 & 34.0 & 125 & 60.8 & 22.0 & 9.7 & 19.5 \\
\hline Saved-water height & $\mathrm{m}$ & 49 & 8 & 2.5 & 45 & 4 & 4 & 1 & 2 \\
\hline Average flow & $\mathrm{m}^{3} / \mathrm{s}$ & 612 & 615 & 634 & 1610 & 1740 & 1990 & 2020 & 2050 \\
\hline Saved-water Level & $\mathrm{m}$ & 780 & 645 & 440 & 375 & 223 & 157 & 126 & 112 \\
\hline$H_{\mathrm{m}, \mathrm{j}}$ & $\mathrm{m}$ & 750 & 641 & 438.5 & 345 & 221 & 155 & 125.5 & 111 \\
\hline$H_{\mathrm{I}, \mathrm{j}}$ & $\mathrm{m}$ & 731 & 637 & 437.5 & 330 & 219 & 153 & 125 & 110 \\
\hline$H_{\mathrm{O}, \mathrm{j}}$ & $\mathrm{m}$ & 620.3 & 461 & 403.5 & 205 & 158.2 & 131 & 115.3 & 90.5 \\
\hline$X_{\mathrm{s}, \mathrm{j}}$ & $\mathrm{m}$ & 6000 & 1000 & 1300 & 8000 & 8500 & 1300 & 500 & 1600 \\
\hline$X_{\mathrm{m}, \mathrm{j}}$ & $\mathrm{m}$ & 16000 & 3000 & 8300 & 16000 & 18000 & 5500 & 6000 & 8000 \\
\hline$X_{\mathrm{e}, \mathrm{j}}$ & $\mathrm{m}$ & 520000 & 17500 & 109600 & 1465800 & 6610000 & 34600 & 72600 & 190000 \\
\hline Average in-Flow & $\mathrm{m}^{3} / \mathrm{s}$ & 612 & 615 & 634 & 1610 & 1740 & 1900 & 1910 & 2050 \\
\hline Lowest in-Flow & $\mathrm{m}^{3} / \mathrm{s}$ & 306 & 307 & 317 & 805 & 870 & 950 & 1010 & 102 \\
\hline High in-Flow & $\mathrm{m}^{3} / \mathrm{s}$ & 2203 & 2214 & 2882 & 4150 & 4550 & 4840 & 5272 & 5380 \\
\hline Normal in-Flow & $\mathrm{m}^{3} / \mathrm{s}$ & 1024 & 1030 & 1068 & 2520 & 2860 & 3100 & 3340 & 3510 \\
\hline Pipe Dia. & $\mathrm{m}$ & 8 & 9 & 9 & 10 & 10 & 10 & 7.5 & 11 \\
\hline Pipe Angle & degree & $50^{\circ}$ & $50^{\circ}$ & $50^{\circ}$ & $50^{\circ}$ & $50^{\circ}$ & $50^{\circ}$ & $50^{\circ}$ & $50^{\circ}$ \\
\hline Bar length & $\mathrm{m}$ & 1104 & 470 & 395.5 & 735.5 & 525 & 1160 & 274 & 630 \\
\hline Bar height & $\mathrm{m}$ & 178 & 58. 5 & 62.2 & 192216.5 & 110 & 78. 5 & 28 & 63 \\
\hline Height of bar top & $\mathrm{m}$ & 791 & 658.7 & 449.2 & 382 & 233 & 174.5 & 135 & 130 \\
\hline $\begin{array}{l}\text { Water volume consumed in per } \\
\text { unit electric energy output }\end{array}$ & $\mathrm{m}^{3} / \mathrm{kWh}$ & 3.6161 & 2.5147 & 11.7393 & 3.3364 & 6.9034 & 19.1357 & 42.4738 & 20.7343 \\
\hline
\end{tabular}


Table 2. The data for coal-fired plants

\begin{tabular}{|c|c|c|c|c|c|c|c|c|c|c|c|c|}
\hline Plant No. & $\mathrm{T} 1$ & $\mathrm{~T} 2$ & $\mathrm{~T} 3$ & $\mathrm{~T} 4$ & $\mathrm{~T} 5$ & T6 & $\mathrm{T} 7$ & $\mathrm{~T} 8$ & T9 & $\mathrm{T} 10$ & $\mathrm{~T} 11$ & T12 \\
\hline $\begin{array}{l}\text { Installed capac- } \\
\text { ity/MW }\end{array}$ & $2 * 600$ & $2 * 600$ & $2 * 600$ & $2 * 600$ & $2 * 300$ & $2 * 125$ & $2 * 360$ & $2 * 330$ & $2 * 220$ & $2 * 135$ & $2 * 300$ & $2 * 135$ \\
\hline$a_{T} / \mathrm{g} / \mathrm{kWh}^{2}$ & 92.6156 & 39.3645 & 190.0658 & 179.0296 & 761.3214 & 981.0396 & 271.1672 & 47.7373 & 59.599 & 672.6546 & 751.5795 & 763.6358 \\
\hline$b_{T} / \mathrm{g} / \mathrm{kWh}$ & -111140 & -47238.41 & -228080.2 & -214836.6 & -456794.3 & -245266 & -195243.7 & -31508.7 & -26226.2 & -181620 & -450950 & -206198 \\
\hline$c_{T} / \mathrm{g}\left(\times 10^{8}\right)$ & 1.756 & 1.445 & 2.1068 & 2.0245 & 1.4991 & 0.51579 & 1.309 & 0.94728 & 0.66685 & 0.52489 & 1.4903 & 0.54147 \\
\hline$W_{T n}$ & 4.2125 & 3.8592 & 4.2124 & 4.0863 & 4.8203 & 16.9678 & 4.7258 & 4.8202 & 16.9696 & 17.4374 & 4.8200 & 17.4376 \\
\hline
\end{tabular}

$W_{T n}$ : Coal to water volume consumed in per unit electric energy output

Table 3. The electric power dispatch of hydro-thermal power systems and electric power of single machine for different load level in high in-flow hour

\begin{tabular}{|c|c|c|c|c|c|c|c|c|}
\hline Load & MW & 4238.76 & 6162.34 & 8288.27 & 10249.36 & 13369.92 & 16270.73 & 17936.46 \\
\hline $\begin{array}{l}\text { MW of hydro } \\
\text { plant }\end{array}$ & MW & 4238.76 & 6162.34 & 6599.37 & 6599.37 & 6599.37 & 8214.20 & 9326.46 \\
\hline $\begin{array}{c}\text { MW of coal-fired } \\
\text { plant }\end{array}$ & MW & 0.00 & 0.00 & 1688.90 & 3649.99 & 6770.55 & 8056.53 & 8610.00 \\
\hline MW of H1 plant & MW & $4 * 0.00$ & $4 * 190.70$ & $4 * 299.96$ & $4 * 299.96$ & $4 * 299.96$ & $4 * 299.96$ & $4 * 299.96$ \\
\hline MW of $\mathrm{H} 2$ plant & MW & $6 * 200.00$ & $6 * 200.00$ & $6 * 200.00$ & $6 * 200.00$ & $6 * 200.00$ & $6 * 200.00$ & $6 * 200.00$ \\
\hline MW of $\mathrm{H} 3$ plant & MW & $3 * 0.00$ & $3 * 0.00$ & $3 * 0.00$ & $3 * 0.00$ & $3 * 0.00$ & $3 * 135.00$ & $3 * 135.00$ \\
\hline MW of H4 plant & MW & $7 * 434.11$ & $7 * 599.93$ & $7 * 599.93$ & $7 * 599.93$ & $7 * 599.93$ & $7 * 599.93$ & $7 * 599.93$ \\
\hline MW of H5 plant & MW & $4 * 0.00$ & $4 * 0.00$ & $4 * 0.00$ & $4 * 0.00$ & $4 * 0.00$ & $4 * 302.46$ & $4 * 302.46$ \\
\hline MW of H7 plant & MW & $6 * 0.00$ & $6 * 0.00$ & $6 * 0.00$ & $6 * 0.00$ & $6 * 0.00$ & $6 * 0.00$ & $6 * 9.38$ \\
\hline MW of H8 plant & MW & $4 * 0.00$ & $4 * 0.00$ & $4 * 0.00$ & $4 * 0.00$ & $4 * 0.00$ & $4 * 0.00$ & $4 * 149.99$ \\
\hline MW of T1 plant & MW & $2 * 0.00$ & $2 * 0.00$ & $2 * 0.00$ & $2 * 312.30$ & $2 * 600.00$ & $2 * 600.00$ & $2 * 600.00$ \\
\hline MW of T2 plant & MW & $2 * 0.00$ & $2 * 0.00$ & $2 * 600.00$ & $2 * 600.00$ & $2 * 600.00$ & $2 * 600.00$ & $2 * 600.00$ \\
\hline MW of T3 plant & MW & $2 * 0.00$ & $2 * 0.00$ & $2 * 0.00$ & $2 * 312.70$ & $2 * 600.00$ & $2 * 600.00$ & $2 * 600.00$ \\
\hline MW of T4 plant & MW & $2 * 0.00$ & $2 * 0.00$ & $2 * 244.45$ & $2 * 600.00$ & $2 * 600.00$ & $2 * 600.00$ & $2 * 600.00$ \\
\hline MW of T5 plant & MW & $2 * 0.00$ & $2 * 0.00$ & $2 * 0.00$ & $2 * 0.00$ & $2 * 133.60$ & $2 * 300.00$ & $2 * 300.00$ \\
\hline MW of T7 plant & MW & $2 * 0.00$ & $2 * 0.00$ & $2 * 0.00$ & $2 * 0.00$ & $2 * 360.00$ & $2 * 360.00$ & $2 * 360.00$ \\
\hline MW of T8 plant & MW & $2 * 0.00$ & $2 * 0.00$ & $2 * 0.00$ & $2 * 0.00$ & $2 * 191.67$ & $2 * 330.00$ & $2 * 330.00$ \\
\hline MW of T9 plant & MW & $2 * 0.00$ & $2 * 0.00$ & $2 * 0.00$ & $2 * 0.00$ & $2 * 0.00$ & $2 * 212.78$ & $2 * 220.00$ \\
\hline MW of T10 plant & MW & $2 * 0.00$ & $2 * 0.00$ & $2 * 0.00$ & $2 * 0.00$ & $2 * 0.00$ & $2 * 0.49$ & $2 * 135.00$ \\
\hline MW of T11 plant & MW & $2 * 0.00$ & $2 * 0.00$ & $2 * 0.00$ & $2 * 0.00$ & $2 * 300.00$ & $2 * 300.00$ & $2 * 300.00$ \\
\hline MW of T12 plant & MW & $2 * 0.00$ & $2 * 0.00$ & $2 * 0.00$ & $2 * 0.00$ & $2 * 0.00$ & $2 * 0.00$ & $2 * 135.00$ \\
\hline
\end{tabular}


Table 4. The electric energy production of hydro-thermal power systems and energy component of hydro plants for different load level in high in-flow hour

\begin{tabular}{|c|c|c|c|c|c|c|}
\hline Load & MW & 6162.34 & 10249.36 & 13369.92 & 16270.73 & 17936.46 \\
\hline Electric energy produced in $T$ & $\mathrm{kWh}$ & 6162340.00 & 10249360.00 & 13369920.00 & 16270730.00 & 17936460.00 \\
\hline$E_{T}$ /percentage & $\mathrm{kWh}$ & $6162340.00 / 100.00$ & $6599366.45 / 64.39$ & $6599366.45 / 49.36$ & $8214200.36 / 50.48$ & $9326460.00 / 52.00$ \\
\hline$E_{G} /$ percentage & $\mathrm{kWh}$ & $0.00 / 0.00$ & $3649993.55 / 35.61$ & $6770553.55 / 50.64$ & $8056529.64 / 49.52$ & $8610000.00 / 48.00$ \\
\hline Share of $f_{1}$ in $E_{G}$ /percentage & $\mathrm{kWh}$ & $176170.75 / 2.8588$ & $185478.51 / 2.8106$ & $185478.51 / 2.8106$ & $240112.90 / 2.9231$ & $365469.36 / 3.9186$ \\
\hline Share of $f_{2}$ in $E_{G}$ /percentage & $\mathrm{kWh}$ & $21763.80 / 0.3532$ & $24708.59 / 0.3744$ & $24708.59 / 0.3744$ & $45305.26 / 0.5515$ & $82046.25 / 0.8797$ \\
\hline Share of $f_{3}$ in $E_{G}$ /percentage & $\mathrm{kWh}$ & $5265952.61 / 85.453$ & $5609409.21 / 84.999$ & $5609409.21 / 84.999$ & $7141210.74 / 86.937$ & $8078269.18 / 86.616$ \\
\hline $\begin{array}{c}\text { Share of } f_{4}+f_{5}+f_{6} \text { in } \\
E_{G} \text { percentage }\end{array}$ & $\mathrm{kWh}$ & $698452.84 / 11.3342$ & $779770.13 / 11.8158$ & $779770.13 / 11.8158$ & $787571.45 / 9.5879$ & $800675.21 / 8.5850$ \\
\hline
\end{tabular}

in per unit electric energy output, the hydroelectric plants have much more superiority to be scheduled for electric energy production than coal-fired plants when the load is smaller. For example, when the load is $4238.76 \mathrm{MW}$, the hydroelectric plant $\mathrm{H} 2$ is first in full power output, and plant $\mathrm{H} 4$ is for the remainder of the load; when the load is $6162.34 \mathrm{MW}, \mathrm{H} 2$ and $\mathrm{H} 4$ is first in full power output, and $\mathrm{H} 1$ is for the remainder of the load, as shown in Table 3. With increases in the load, the coal-fired plants with smaller coal-water consumption volume are also gradually put into schedule for electric energy production till the load arrives at the sum of the rated install capacity of all hydroelectric and coal-fired plants, as shown in Table 3.

Table 4 shows the electric energy production of hydro-thermal power systems and energy component of hydro plants for different load level in high in-flow hour. When the load is small, higher percentage of electric energy production is shared by hydroelectric plants than coal-fired plants, while lower percentage is shared by hydroelectric plants than coal-fired plants, as shown in Table 4. With increase in load, the percentage shared by hydroelectric plants increases, while the percentage shared by coal-fired plants decreases, as shown in Figure 2 and Figure 3. It is also seen that for a load of about 7000MW of load, hydroelectric plants take $100 \%$ and coal-fired plants takes 0 .
With increase in load, the percentage shared by hydroelectric plants increases, while the percentage shared by coal-fired plants decreases, as shown in Figure 2 and Figure 3. It is also seen that for small than about $7000 \mathrm{MW}$ of load, hydroelectric plants take $100 \%$ and coal-fired plants takes 0 .

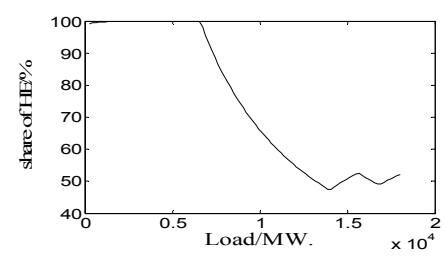

Figure 2. Sharing percentage of electric energy produced by hydro plants (HE: Electric energy produced by hydro plants)

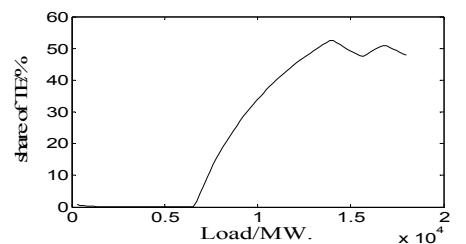

Figure 3. Sharing percentage of electric energy produced by coal-fired plants(TE: Electric energy produced by hydro plants)

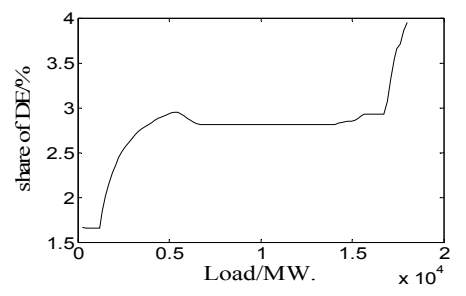

Figure 4. Sharing percentage of electric energy converted from water-deep pressure energy (DE: Electric energy converted from water-deep pressure energy) 


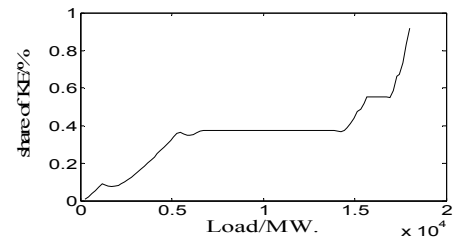

Figure 5. Sharing percentage of electric energy converted from kinetic energy (KE: Electric energy converted from kinetic energy)

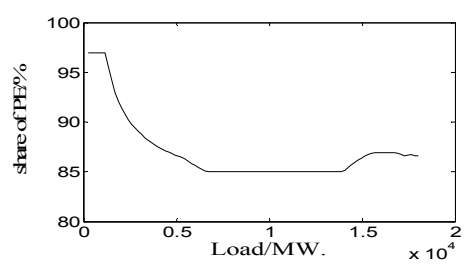

Figure 6. Sharing percentage of electric energy converted from potential energy (PE: Electric energy converted from potential energy)

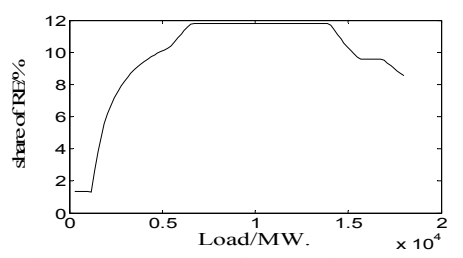

Figure 7. Sharing percentage of electric energy converted from reservoir energy (RE: Electric energy converted from reservoir energy)

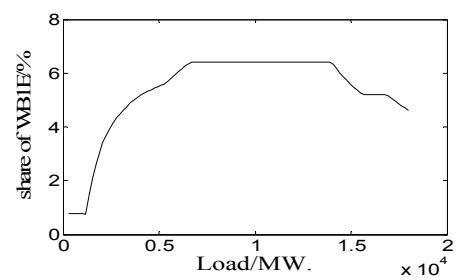

Figure 8. Sharing percentage of electric energy converted from reservoir energy in WB1 (WB1E: Electric energy converted from reservoir energy in WB1)

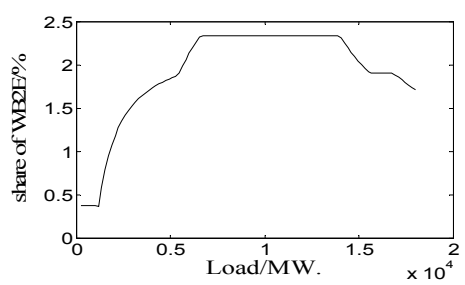

Figure 9. Sharing percentage of electric energy converted from reservoir energy in $\mathrm{W}$

With increase in load, water-deep pressure energy and kinetic energy increases, as shown in Figure 4 and Figure 5, and potential energy decreases, as shown in Figure 6, while reservoir energy increases first, and

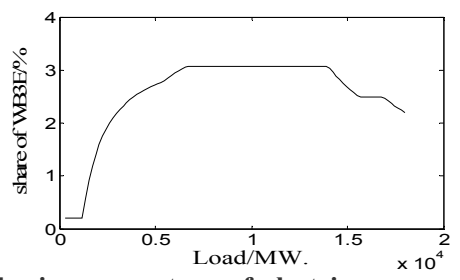

Figure 10. Sharing percentage of electric energy converted from reservoir energy in WB3

then decreases, as shown in Figure 7. It is also seen that these percentage retains constant from 7000MW to $14000 \mathrm{MW}$.

With increase in load, the percentage of electric energy converted from reservoir energy of reservoir water body WB1, WB2 and WB3 included in the total electric energy produced by hydroelectric plants all increases, but retains constant from $7000 \mathrm{MW}$ to $14000 \mathrm{MW}$, as shown in Figure 8-Figure 10.

\section{Conclusions}

1) Optimal scheduling for electric energy production of hydro-thermal power systems depends on such factors as load demand, the water-consumed volume increment rate, the in-flow of reservoir, and so on. The plant with low water-consumed volume increment rate is first scheduled for electric energy production, and the plant with the highest water-consumed volume increment rate is finally scheduled for production.

2) In different flow hour, the sharing percentage of the electric energy produced by hydroelectric and coal-fired plants is dependent on some factors, such as the demand load, the coming flow of reservoir, and so on. In high in-flow hour, the percentage shared by hydroelectric plants may be high for small load demand and is low for great load, while the percentage shared by coal-fired plants may be low for small load demand and is high for great load. In low in-flow hour, the percentage shared by hydroelectric plants may be low for any load demand, while the percentage shared by coal-fired plants may be high for any load demand.

\section{Acknowledgements}

The author greatly acknowledges the financial support of 
the National High Technology Research and Development Program of China (863 Program) (2007AA04Z 197), National Natural Science Foundation of China (50767001), Nature Science Foundation of Guangxi (0640028), Program for 100 Young and Middle-aged Disciplinary Leaders in Guangxi Higher Education Institutions (RC20060808002), Science and Technology Project of Guangxi Education Administration (200808 MS150) and Guangxi Innovation Plan in Graduate Education.

\section{REFERENCES}

[1] Fleten S. E., Wallace S. W., and Ziemba W. T., "Portfolio management in a deregulated hydropower based electricity market," In Proceedings of the 3rd International Conference on Hydropower Development, pp. 197-204, 1997.

[2] Fleten S. E., Wallace S. W., and Ziemba W. T., "Hedging electricity portfolios via stochastic programming," IMA volumes on Mathematics and Its Applications, Vol. 128, pp. 71-93, 2002.

[3] Ilyas Eker, "The design of robust multi-loop-cascaded hydro governors," Engineering Computer, Vol. 20, No. 2, pp. 45-53, 2004.

[4] Wallace S. W. and Fleten S. E., "Stochastic programming models in energy," The series Handbooks in Operations Research and Management Science, Vol. 10, pp. 637-677, 2003.

[5] Guan X., Svoboda A., and Li C. A., "Scheduling hydro power systems with restricted operating zones and discharge ramping constraints," IEEE Transactions on Power System, Vol.14, No.1, pp. 126-131, 1999.

[6] Yang J. S., and Chen N, "Short term hydrothermal coordination using multipass dynamic programming," IEEE Transactions on Power System, Vol. 4, No. 3, pp. 1050-1056, 1989.

[7] Li C., Jap P., and Streiffert D, "Implementation of network flow programming to the hydrothermal coordination in an energy management system," IEEE Transactions on Power System, Vol. 8, No. 3, pp. 1045-1053, 1993.

[8] Rosenthal R. E., "A nonlinear network flow algorithm for maximization of benefits in a hydroelectric power system," Operation Research, Vol. 29, No. 4, pp. 763-786, 1981.

[9] Chang G. W., Aganagic M., Waight J. G., et al., "Experiences with mixed integer linear programming based approaches on short-term hydro scheduling," IEEE Transactions on Power Systems, Vol. 16, No. 4, pp. 743-749, 2001.

[10] Conejo A. J., Arroyo J. M., Contreras J., et al., "Self-scheduling of a hydro producer in a pool-based electricity market," IEEE
Transactions on Power System, Vol. 17, No. 4, pp. 1265-1272, 2002.

[11] Chang G., Mohamed Aganagic W, Waight James G, et al., "Experiences with mixed integer linear programming based approaches on short-term hydro scheduling," IEEE Transactions on Power System, Vol. 16, No. 4, pp. 743-749, 2001.

[12] Nilsson O. and Sjelvgren D., "Mixed integer programming applied to short-term planning of a hydro-thermal system," IEEE Transactions on Power System, Vol. 11, No. 1, pp. 281-286, 1996.

[13] Sinha N., Chakrabarti R., and Chattopadhyay P. K., "Fast evolutionary programming techniques for short-term hydrothermal scheduling," Electric Power Systems Research, Vol. 66, pp. 97-103, 2003.

[14] Zoumas C. E., Bakirtzis A. G., Theocharis J. B., et al., "A genetic algorithm solution approach to the hydrothermal coordination problem," IEEE Transactions on Power System, Vol. 19, No. 2, pp. 1356-1364, 2004.

[15] Guan X., Ni E., and Li R., “An optimization-based algorithm for scheduling hydrothermal power systems with cascaded reservoirs and discrete hydro constraints," IEEE Transactions on Power System, Vol. 12, No. 4, pp. 1775-1780, 1997.

[16] Jiang C. W. and Etorre B., "A self-adaptive chaotic particle swarm algorithm for short term hydroelectric system scheduling in deregulated environment," Energy Conversion and Management, Vol. 46, No. 17, pp. 2689-2696, 2005.

[17] Yu B. H., Yuan X. H., and Wang J. W., "Short-term hydro-thermal scheduling using particle swarm optimization method," Energy Conversion and Management, Vol. 48, No. 7, pp. 1902-1908, 2007.

[18] Umayal S. P. and Kamaraj N., "Stochastic multi objective short term hydrothermal scheduling using particle swarm optimization," In Indicon Annual IEEE, pp. 497-501, 2005.

[19] Esmin A. A. A., Lambert-Torres G., and Zambroni de Souza A. C., "A hybrid particle swarm optimization applied to loss power minimization," IEEE Transactions on Power System, Vol. 20, No. 2, pp. 855-859, 2005.

[20] Abido M. A., "Optimal power flow using particle swarm optimization," Electrical Power Energy System, Vol. 24, pp. 563-571, 2002.

[21] Zambelli M., Siqueira T. G., Cicogna M., et al., "Deterministic versus stochastic models for long term hydrothermal scheduling," In Proceedings of IEEE Power Engineering Society General Meeting, 2006.

[22] Heredia F. J., Nabonal N. L., "Optimum short-term hydrothermal scheduling with spinning reserve through network flows," IEEE Transactions on Power System, Vol. 10, No. 3, pp. 1642-1651, 1995 